\title{
Trans-Sinusal Frontal Approach for Olfactory Groove Meningiomas
}

\author{
Paul Hallacq, M.D.,' Jean-Jacques Moreau, M.D.,1 Georges Fischer, M.D.,2 \\ and Jean-Luc Béziat, M.D.3
}

\section{ABSTRACT}

The authors report on their experience with the trans-sinusal frontal approach in removing olfactory groove meningiomas. Six tumors were operated on by the trans-sinusal frontal approach, using a bicoronal incision; two tumors developed on one side, and there were four bilateral olfactosellar tumors. Osteotomy of the anterior wall of the frontal sinus was performed with an oscillating saw without any burr hole. The posterior wall of the sinus was resected and the tumor was attacked through a real subfrontal route along the plane of the anterior skull base. Ethmoidal blood supply was controlled at the initial stages of the operation, allowing avascular tumor debulking. Olfactory nerves, invaded by the tumor, were removed along with the tumor. Tumor extensions toward the sella and the optic canals were removed without brain retraction, opening of the Sylvian fissure, or dissection of the carotid arteries. All patients made a good neurologic recovery; intellectual impairment disappeared within 1 month, and visual acuity normalized within 2 weeks. Olfactory nets were preserved on the contralateral side in unilateral tumors. The trans-sinusal frontal approach is technically easy and safe to achieve. Osteotomy and replacement of the anterior wall of the frontal sinus are rapidly performed. When the frontal sinus is small, imageguided surgery allows precise deliniation of its limits and the free bone flap, including the calvarial outer layer, tangentially cut from one supraorbital canal to the other. The cosmetic result is perfect, as the normal contour of the forehead is maintained without any scar or visible burr hole. The trans-sinusal frontal approach gives access to the orbital roofs and to the central anterior skull base from the crista galli to the tuberculum sellae and the anterior clinoid processes. The trans-sinusal frontal approach represents an alternative to conventional cran-

Skull Base, volume 11, number 1, 2001. Reprint requests: Paul Hallacq, M.D., Department of Neurosurgery, Hôpital Dupuytren, 2 Avenue Martin Luther King, 87042 Limoges, France. E-mail: paulhallacq@nomade.fr. 1Department of Neurosurgery, Hôpital Dupuytren, Limoges, France; ${ }^{2}$ Department of Neurosurgery C, Hôpital Pierre Wertheimer, Lyon, France; ${ }^{3}$ Department of Maxillo-Facial Surgery, Hôpital de la Croix-Rousse, Lyon, France. Copyright (C) 2001 by Thieme Medical Publishers, Inc., 333 Seventh Avenue, New York, NY 10001, USA. Tel: +1(212) 584-4662. 1531-5010,p;2001,11,01,035,046,ftx,en;sbs00205x. 
iotomies for tumors developed in the central anterior skull base, especially for olfactory groove meningiomas, whatever their size.

KEYWORDS: Anterior skull base, olfactory groove meningioma, frontal sinus approach

The first description of an olfactory groove meningioma appeared in Cruveilhier's Traité d'anatomie in 1835. The first successful removal of such a tumor is attributed to an Italian surgeon, Francesco Durante in 1885. Cushing in 1938 reported on a series of 28 cases operated on through a unilateral frontal craniotomy and subfrontal approach, with a mortality rate of $19 \% .^{1}$ The unilateral frontal craniotomy is always preferred by some investigators, ${ }^{2}$ sometimes associated with orbital rim osteotomy to decrease brain retraction. ${ }^{3}$ This approach permits early control of tumor arterial supply at the level of the skull base and preservation of the contralateral olfactory filaments. However, wide retraction of the frontal lobe parenchyma, and even partial removal, may be required for contralateral tumor uncapping and removal.

The bilateral frontal craniotomy extended to the orbital rim, or extensive transbasal approach, ${ }^{4-9} \mathrm{a}$ modification of the transbasal approach described by Derome, ${ }^{10}$ allows access to the tumor's basal attachment along the anterior fossa with less frontal lobe retraction, and access to all poles of the tumor; en bloc osteotomy of the orbital roofs and frontal sinus is performed either after ordinary bifrontal craniotomy or in a single bloc. Realization of two consecutive bone flaps is time-consuming and may be deleterious for severely ill patients.

The third preferred surgical approach was first proposed by Kempe. ${ }^{11}$ The pterional route, on the side on which the bulk of tumor is situated, permits early dissection of the posterior pole of the tumor, releasing it from the optic nerves and the cerebral vessels. ${ }^{12-15}$ The frontal sinus is not entered. There is no venous compression by frontal retraction, but ethmoidal vessels are not controlled at the initial stages of the operation, possibly rendering the surgical field obscured by blood; we agree with the authors, who emphasize obliterating the blood supply of meningioma before resecting the tumor. ${ }^{16}$ Moreover, the contralateral tumor component and extensions into the cribriform plate or the sphenoid and the ethmoid sinuses, if any, are more difficult to reach. In our experience, it seems easier to loosen the posterior part of the tumor from the optic nerves and from the pial vessels after internal decompression, when the tumor is debulked and partially devascularized and reduced, which is not easy with this pterional route. The one-and-a-half technique, using both accesses, pterional and subfrontal, at the same time may also be used.

The trans-sinusal frontal approach has been used for reconstruction of the traumatic lesions of craniofacial borders. ${ }^{17-20}$ The authors have extended the indications of this approach ${ }^{21}$ in order to provide improved exposure for intradural tumors of the anterior floor of the skull base, in particular olfactory groove and olfactosellar meningiomas. ${ }^{22}$

\section{MATERIALS AND METHODS}

\section{Clinical Material}

Six patients, aged 39-76, were operated on using the trans-sinusal frontal approach over a 4-year period, 1996-2000. Four tumors were bilateral, olfactosellar encroaching upon the two optic nerves and the diaphragm sellae. Two tumors were implanted on one olfactory groove, one of which extended on 
Table 1 Series Characteristics

\begin{tabular}{|c|c|c|c|c|c|c|}
\hline Case & Sex & Age & Presentation & Location & Histology & Outcome \\
\hline 1 & $F$ & 39 & Headaches & $\begin{array}{l}\text { Unilateral } \\
\text { olfactory groove }\end{array}$ & Meningothelial & $\begin{array}{c}\text { Normal status; } \\
\text { no anosmia }\end{array}$ \\
\hline 2 & $M$ & 58 & $\begin{array}{l}\text { Inappropriate behavior; } \\
\text { anosmia; visual loss }\end{array}$ & $\begin{array}{l}\text { Bilateral } \\
\text { olfactosellar }\end{array}$ & Meningothelial & $\begin{array}{l}\text { Normal status; } \\
\text { anosmia }\end{array}$ \\
\hline 3 & $F$ & 72 & $\begin{array}{l}\text { Headaches; anosmia; } \\
\text { inappropriate behavior }\end{array}$ & $\begin{array}{l}\text { Bilateral } \\
\text { olfactosellar }\end{array}$ & Meningothelial & $\begin{array}{l}\text { Nervous } \\
\text { breakdown }\end{array}$ \\
\hline 4 & $M$ & 76 & $\begin{array}{l}\text { Inappropriate behavior; } \\
\text { anosmia; visual loss }\end{array}$ & $\begin{array}{l}\text { Bilateral } \\
\text { olfactosellar }\end{array}$ & Meningothelial & $\begin{array}{l}\text { Anosmia; } \\
\text { normal status }\end{array}$ \\
\hline 5 & $\mathrm{~F}$ & 70 & $\begin{array}{l}\text { Inappropriate behavior; } \\
\text { anosmia; visual loss }\end{array}$ & $\begin{array}{l}\text { Bilateral } \\
\text { olfactosellar }\end{array}$ & Fibroblastic & $\begin{array}{l}\text { Anosmia; } \\
\text { normal status }\end{array}$ \\
\hline 6 & $M$ & 74 & $\begin{array}{l}\text { Inappropriate behavior; } \\
\text { headaches }\end{array}$ & $\begin{array}{l}\text { Unilateral } \\
\text { olfactory groove }\end{array}$ & Transitional & Normal status \\
\hline
\end{tabular}

the contralateral side under the falx. Clinical presentation and outcome are summarized in Table 1.

\section{Surgical Technique}

\section{SUPERFICIAL EXPOSURE}

The patient was carefully placed in the supine position, with the head fixed in a Mayfield-Kees threepoint head holder, slightly raised above heart level, the neck extended to angle the head backward toward the floor. The line of incision within the hair, not shaved, was infiltrated with $1 \%$ xylocaine and norepinephrine. The skin incision was bicoronal according to Cairns-Unterberger or Souttar, through the subcutaneous and frontalis muscle layers to the periosteum, extending from one tragus to the other. The scalp was elevated in the plane of cleavage between the frontalis muscle and the frontalis periosteum to the upper limits of the frontal sinus. The periosteum was incised at this level transversely between the two superior temporal lines and laterally to the zygomatic processes of the frontal bone. The entire scalp was raised forward to expose the supraorbital ridge bilaterally and the nasal process of the frontal bone up to the fronto-naso-maxillary suture in the midline. The periorbital fascia was dissected following the sub- periostal dissection of the scalp. Dissection of the periorbital fascia was made carefully to avoid orbital fat release. When necessary, the supraorbital foramens were opened with a chisel to free the supraorbital vasculonervous bundles. Orbital roofs and medial walls were exposed to the level of the anterior ethmoidal arteries; these arteries were coagulated and cut in the orbit in two patients. The levator palpebrae, superior rectus, and superior oblique muscles were protected by the periosteum and the periorbita; however, care was taken not to over-retract these fragile structures. A large free fragment of periosteum was taken from the area posterior to the scalp incision. If needed, the fragment extended forward to two centimeters behind the level of periosteal incision. This area of intact periosteum facilitated closure of the deep tissue plane, covering the bone flap.

\section{OSTEOPLASTIC FLAP}

The anterior wall of the frontal sinus was cut monobloc with an oscillating saw, the blade being directed obliquely on a bevel into the center of the sinus so as to facilitate closure and to ensure a solid keystone for bone replacement. The periorbita was protected with malleable retractor blades. Bone osteotomies were first made at the inferior and external limits of the sinus, and the anterior wall of the 
sinus was cut in a single movement in a coronal plane from one side to the other one. The medial orbital roofs were split, and finally the naso-frontomaxillary suture was cut in an inverted V-shaped fashion and loosened with an osteotome. The anterior wall was lifted with a periosteal elevator and a chisel inserted as levers above through the bone cut into the frontal sinus. Intersinus septa were broken with a straight-edged chisel. For small frontal sinus, bone flap extended beyond the limits of the sinus, including the external layer of the frontal vault cut tangentially. Surgical exposure could be enlarged to the orbital roofs, easily when they were pneumatized. The mucous membranes of the sinus were resected to the frontonasal orifices where they were coagulated, cut away, and pushed downward into the nasal cavity. The entire mucosal and inner cortical lining of the anterior and posterior walls of the sinus were removed with a rotatory cutting burr. The posterior wall of the sinus was perforated, and the dura mater was dissected from the undersurface of the posterior wall, which was removed. Particular care was used during the dissection on the median line, where the internal frontal crest was invaginated in the dura mater. The dura mater was separated from the crista galli, which was removed with rongeurs. The working space in- cluded the anterior floor of the skull with the medial orbital walls and orbital roofs laterally on each side, and the anterior aspect of the ethmoid in the center (Fig. 1).

\section{TUMOR RESECTION}

The dura mater was opened transversely on either side of the midline near the frontal base at the junction between the convexity and the base. The falx with the origin of the superior sagittal sinus was ligated and cut at the cecal foramen. The olfactory nets, invaded by the tumor, were coagulated during the control of the ethmoidal vessels at the level of the cribriform plate. The olfactory tracts were protected on the healthy side, when the tumor was developed on one side. Cribriform intracranial openings were occluded with coagulation and bone wax. When the ethmoidal arterial supply was important, intraorbital control was useful. After the basal arterial supply was controlled and the tumor widely devascularized, we proceeded to hollow the tumor by fragmentation with an ultrasonic aspirator. At the completion of the debulking, the dural attachment was carefully coagulated, and tumor remnants were eliminated with a rotatory diamond
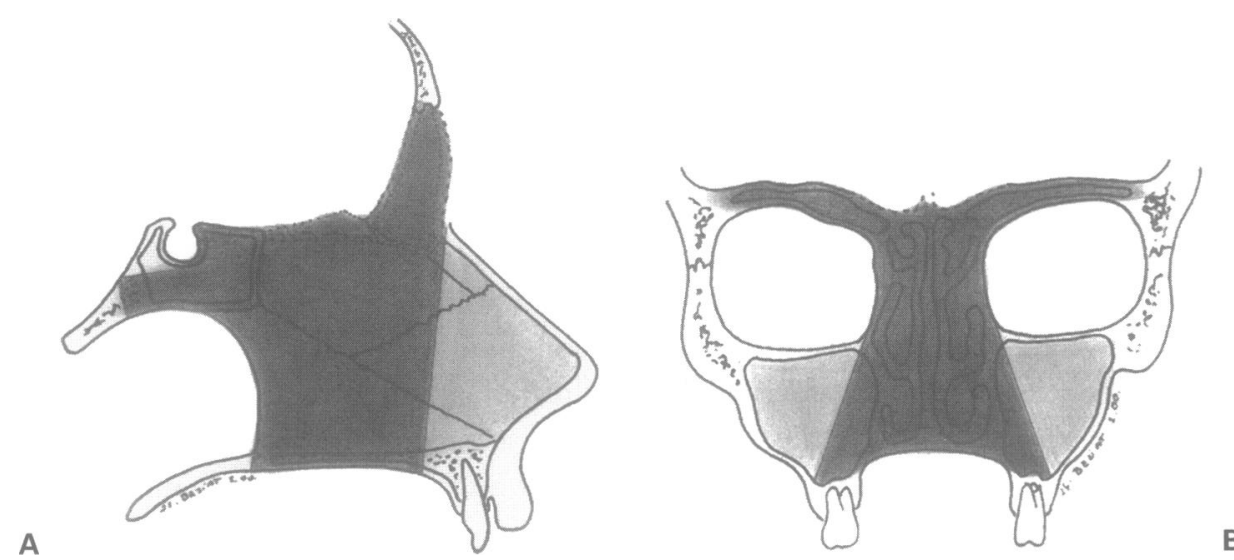

Figure 1 Schematic drawings showing the extent of surgical exposure gained with the osteoplastic trans-sinusal frontal approach. (A) Sagittal view. (B) Frontal view. Black, direct view; gray, indirect view. 
drill. Invaded dura mater was removed until the healthy zone was reached. All these surgical maneuvers were made without any risk to the frontal lobes detached away from the orbital roofs and ethmoid by gravity. Sphenoid hyperostosis was often vascular, including sometimes an extension of the sphenoid sinus. The dura mater was peeled from the hyperostosis, which was not removed, if not invaded, in order to decrease the risk of postoperative cerebrospinal fluid (CSF) leak. The posterior part of the hyperostosis projected at the level of the internal carotid arteries and optic nerves. Tumor debulking was stopped at this level. The tumor capsule was loosened back to the sphenoid wing, which served as a landmark to progress medially to the anterior clinoid processes and the optic nerves. The operating microscope was set up. A plane of arachnoidal dissection was allowed to free the posterior pole of the tumor gradually from the frontal parenchyma, the frontopolar arteries, which were dissected and coagulated, and from the optic nerves in the optic foramina. Tumor fragments overhanging the tuberculum sellae and diving in the direction of the diaphragm sellae were carefully dissected away from the pituitary stalk. Wide moistened cottons introduced between the posterior pole of the tumor and the brain maintained the frontal lobes at some distance, avoiding any instrumental brain retraction.

\section{CLOSURE}

Osseous reconstruction of the skull base with bone was unnecessary. Frontonasal ducts were occluded by means of osseous fragments, periosteum, reinforced by fibrin glue. The dura mater was reconstructed with a periosteum graft sutured as watertight as possible. A wide fragment of periosteum was affixed within the deadspace between the frontobasal dura mater and the anterior wall of the sinus, maintained by fibrin glue. The frontal curve was reconstituted by repositioning the anterior wall of the frontal sinus, so that the beveled bone edges were in good approximation, maintained by two transosseous absorbable sutures and covered with the periosteum sutured to the temporal fascia laterally. The scalp was closed in the usual manner.

\section{RESULTS}

The six patients made an uneventful neurologic recovery. Restoration of normal mental function occurred within 1 month in the four patients who presented inappropriate behavior preoperatively. Visual acuity normalized within 2 weeks in the three patients who suffered visual loss before surgery. Olfactory sense was preserved in the two patients harboring unilateral tumors.

Postoperative head CT scan did not show any abnormality. Cosmetic result was perfect with normal forehead contour and no visible scar in all patients.

\section{ILLUSTRATIVE CASE}

A 58-year-old man was referred to the ophthalmologist for visual loss. Papilledema was present on both sides. Because the patient was exhibiting inappropriate behavior, a head CT scan was immediately performed (Fig. 2). It showed an enhancing tumor developed in the olfactosellar region on both sides. The patient had a history of memory disturbances and of aggressiveness of 8-year's duration. $\mathrm{He}$ was unable to work any more as a farmer. Neurologic examination showed a typical frontal syndrome, anosmia, and the visual loss for which he was referred. Workup included an angiogram and an MRI (Figs. 3, 4).

The trans-sinusal approach was used to remove the olfactosellar meningioma. Total tumor removal was possible without any brain retraction, in particular at the level of the optic canals. There was no blood loss. Postoperative course was un- 
A
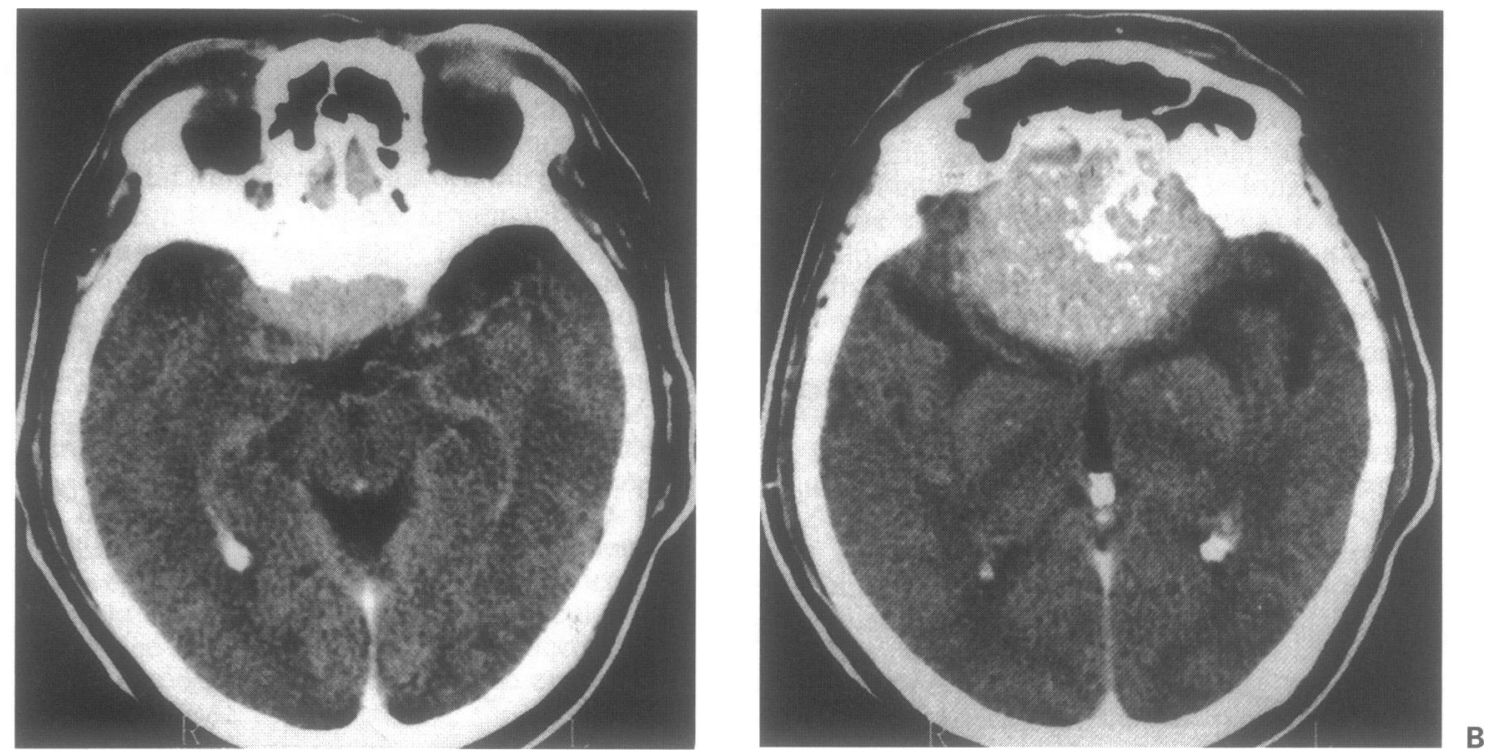

Figure 2 (A, B) Head CT scan showing an enhancing homogeneous mass with some calcifications behind the frontal sinus. The tumor extends to the diaphragm sellae.
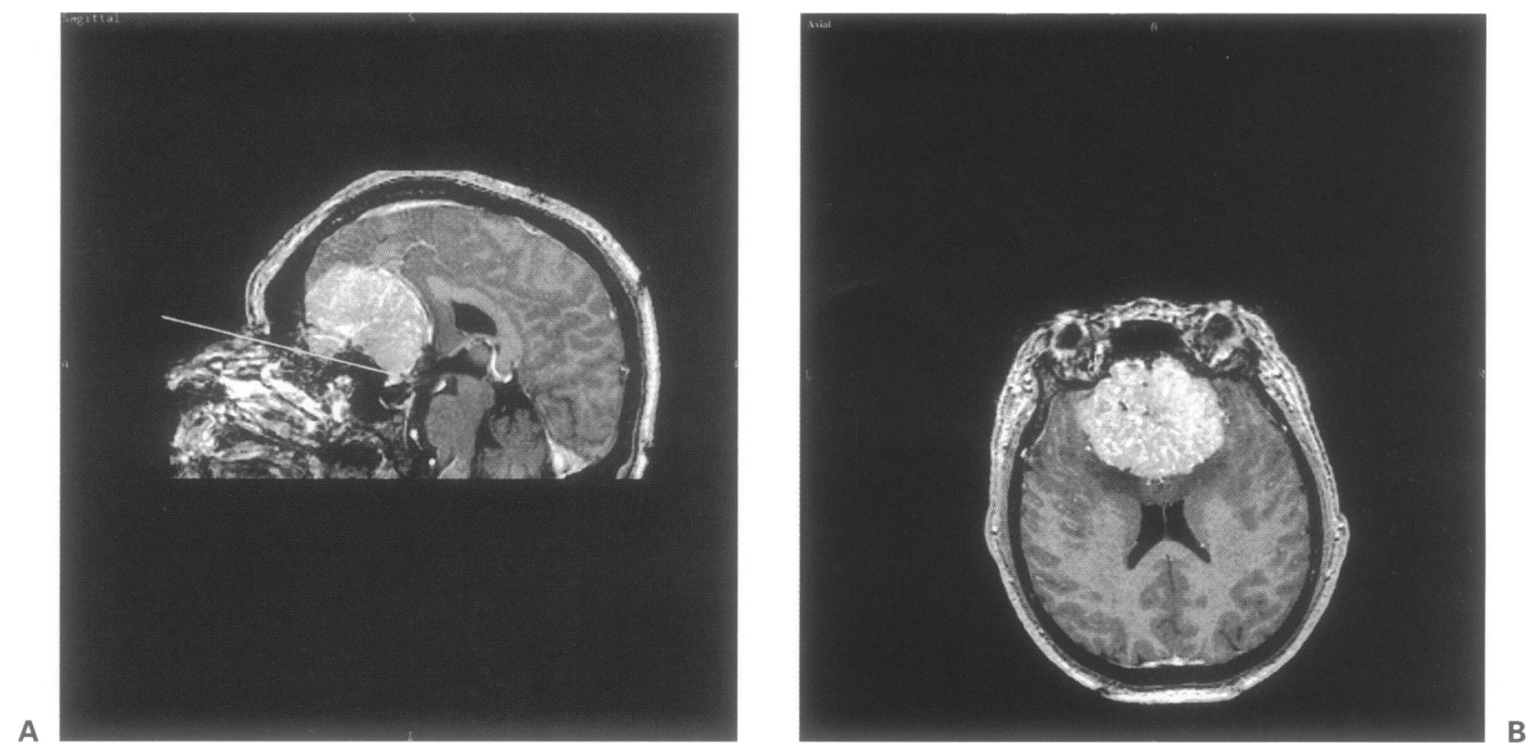

Figure 3 Cerebral MRI. (A) Sagittal view. (B) Axial view. The superior limit of the tumor faces that of the frontal sinus. The yellow marker follows the skull base and the dural implantation. 

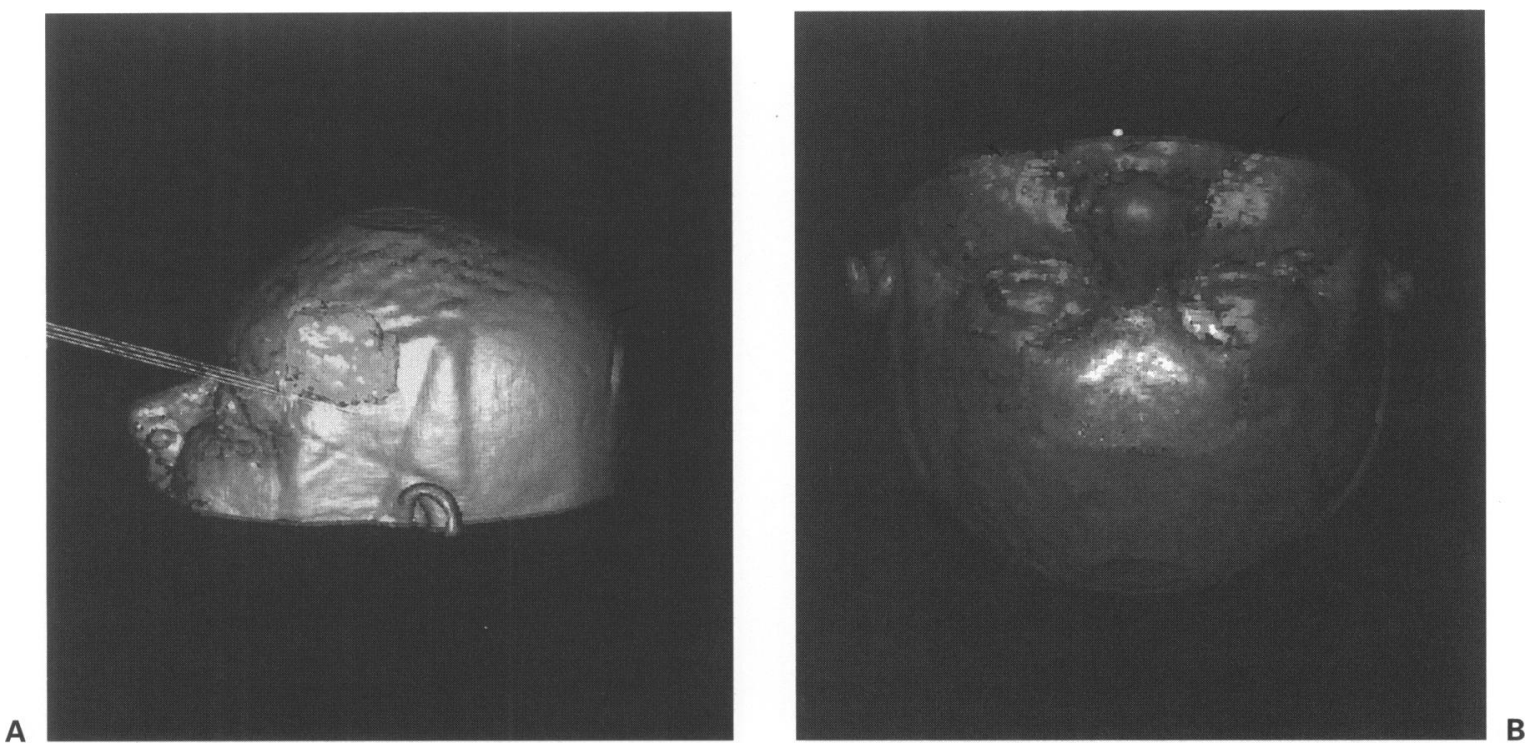

Figure 4 Three-dimensional reconstruction. (A) Sagittal view. (B) Operative view. Relationships between the tumor and the frontal sinus.

eventful. Control head CT scan showed no complications (Fig. 5). Intellectual functions were restored within one month; visual acuity went from $2 / 10$ to $6 / 10$ within 2 weeks. At 1 -year follow-up, the result has been maintained.

\section{DISCUSSION}

The anterior osteoplastic approach to frontal sinus was described in the late nineteenth century by Schonborn in 1894 and by Briger in 1895 for chronic infections of the frontal sinus. The technique was later modified by Winkler and Hoffman in 1904 and by Beck in 1908. At the same time, hypophysis tumors were approached by craniectomy of the frontal sinus. With the exception of Giordano and Hochenegg, and later of Von Eiselsberg, who repositioned the anterior wall of the sinus, the anterior wall of the sinus was not replaced. After Frazier in 1913, the frontal sinus was no longer used to approach the sella turcica. ${ }^{23}$
The osteoplastic approach of the frontal sinus for sinusitis fell into disuse for numerous years in favor of surgical routes approaching the sinus by its lower face. Renewed interest for osteoplastic approach came during the 1950s and 1960s with Gibson and Walker, ${ }^{24}$ Macbeth, ${ }^{25}$ Tato et al., ${ }^{26}$ Bergara and Itoiz, ${ }^{27}$ and Goodale and Montgomery. ${ }^{28,29}$ The incision followed the margins of the eyebrow unilaterally or bilaterally in wing butterfly. Gibson and Walker were using the bicoronal incision from 1951.24 Osteotomy of the anterior wall, maintained attached to the scalp by the periosteum, was made with a chisel, a bit, or by means of a circular or oscillating saw. From 1954, in addition to the classic indications of severe irreversible chronic sinusitis, mucoceles, pyoceles, frontal osteomas, and traumatism of the frontal sinus, the trans-sinusal frontal approach was proposed to gain access to the anterior floor of the base of the skull and to repair ethmoidal CSF leaks. ${ }^{23}$

Regarding permeability of the frontal sinus, two divergent points of view were considered. Proponents of conservation of the sinus lumen lauded 
A
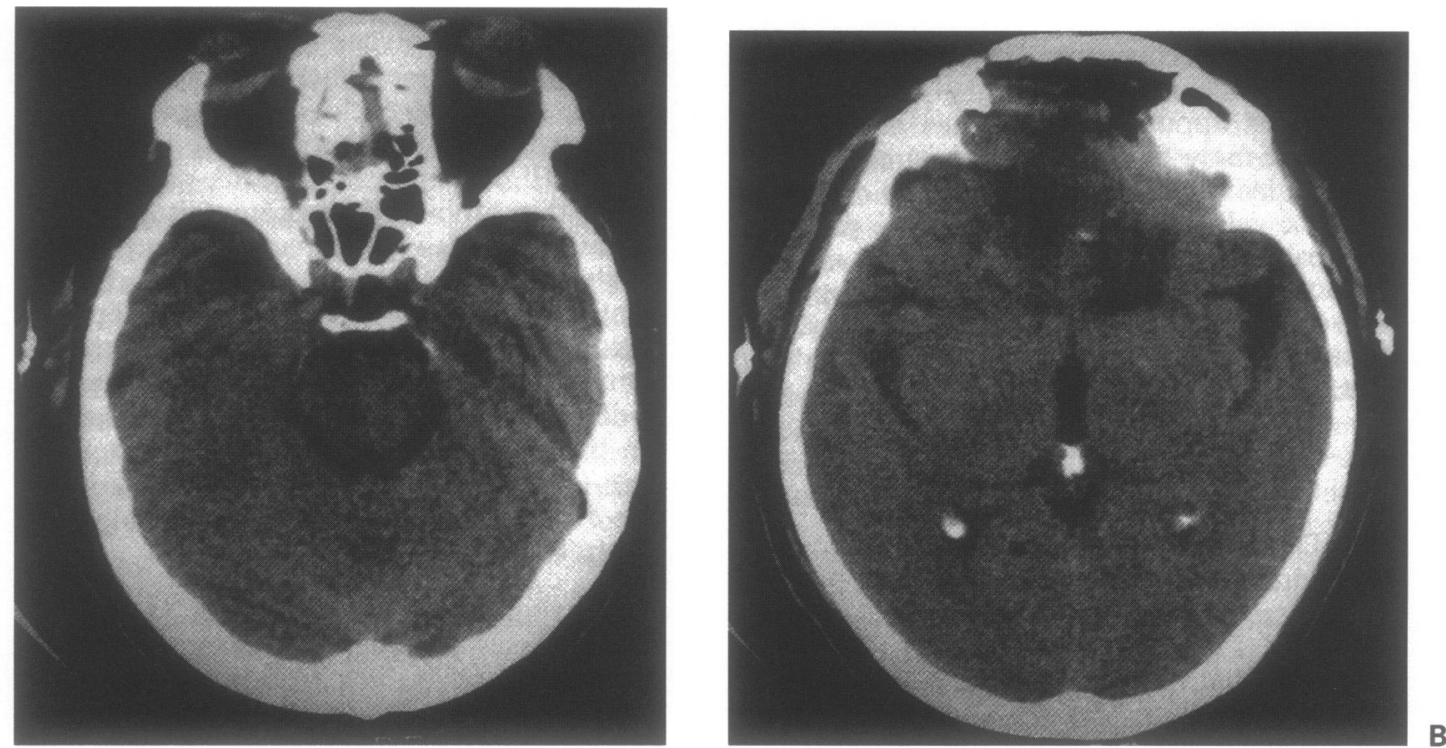

Figure 5 (A,B) Postoperative CT scan of the head. Cerebral edema is still present. Some air is located within the deadspace between the dura and the bone flap. The forehead contour is cosmetically perfect.

the improvement of the intranasal drainage of the frontonasal duct by protecting all or any of the mucous membranes of the sinus and by ensuring the permeability of the frontonasal duct by simple dilatation, flaps using nasal mucous membranes, free skin grafts, expansion of the frontonasal ducts by tantalum, rubber, or acrylic tubes. Proponents of obliteration of the frontal sinus achieved complete and meticulous removal of the mucous membranes of the sinus respecting that of the infundibulum, which was inverted downward in the frontonasal duct, before obliterating the canal with autogenous or alloplastic materials by means of fascia lata, flaps of periosteum, fat, fibrous, or osseous fragments. The principle of elimination of the sinus cavity or sinus cranialization was initiated, even though the posterior wall of the frontal sinus was preserved. Malecki removed the two walls of the sinus. ${ }^{30}$ The free space filled in 5-8 days under the combined forward pressure of the dura mater and of the brain. The same author proposed closing the frontonasal orifice with a periosteal graft.

The trans-sinusal frontal approach has been proposed for intracranial or intraorbital tumors only as the first step of a subsequent realization of a bifrontal or fronto-orbital bone flap, ${ }^{31-34}$ or as an extension of a bifrontal craniotomy. Osteotomy of the anterior wall of the frontal sinus with the adjacent calvarial outer layer with an oscillating saw, without any burr hole, has never been reported for intradural tumors. Indeed, infectious complications related to frontal sinus opening are dreaded.

The trans-sinusal frontal approach has several advantages. Bone osteotomy and flap replacement are rapid. The time of intervention is reduced, in particular for the elderly, with regard to large bifrontal approaches. ${ }^{35-38}$ Realization of the osteoplastic flap is facilitated by the width of the sinus; nevertheless, for small frontal sinus, real tangential cut including part of the external layer of the frontal vault gives the same exposure. To optimize bone flap design, the frontal sinus volume may be reconstructed with the neuronavigator and frontal sinus limits accurately mapped. There is no longer any need for an x-ray template. $^{38}$ Lateral extensions of olfactory groove meningiomas are not the rule, making it unnecessary to enlarge laterally the flap to the frontal zy- 
gomatic processes. However, the flap has to exceed the limits of the sinus so as to obtain a harmonious arc of a circle. The reconstruction of the frontal curve is based on the beveled cut of the anterior wall of the sinus, a harmonious frontal keystone, and the periosteal suture that sticks the bone flap. Cosmetically, postoperative result was very satisfactory, as the scalp incision was buried within the scalp. At the forehead level no osseous defect related to the burr holes is observed, contrary to what can be observed with a monobloc frontoorbito-nasal flap, in a region in which the tissue's thickness is limited. ${ }^{40-42}$

Real subfrontal access to the skull abolishes any need of brain retraction, ${ }^{43-45}$ especially because the frontal lobes fall toward the back because of gravity. Therefore, no lumbar drainage has been inserted. The bottom of the frontal sinus falls at the level of the base; it seems logical to use the most direct angle of attack according to the axis of the base. The absence of brain retraction contributes to the decrease in postoperative edema, postoperative contusional hemorrhages or even brain ischemia favored by the compression and/or the sacrifice of the frontal bridging veins. ${ }^{46}$ Also, to avoid brain damage, en bloc removal of the tumor is usually not recommended. Interruption of ethmoid arterial supply is done either by intracranial or by intraorbital approach. ${ }^{47}$ Cervical external carotid control does not seem necessary. ${ }^{48}$ Safe devascularization of the tumor by coagulating and resecting the basal dural attachment allows a dry operative field and facilitates the dissection of the posterior pole of the tumor. It is not useful to open the lateral and the Sylvian fissures, which remain at some distance from the operative cavity. Tumor removal was total, obtaining a grade I described by Simpson ${ }^{49}$ in six meningiomas: two unilateral, and four bilateral olfactosellar.

Olfactory impairment was often an early symptom, but the diagnosis was rarely made before the tumor attained sufficient size to cause visual loss. ${ }^{50}$ Anosmia was not reversible because the olfactory nets were invaded and distended by the tumor and because they were removed during the operation. Surgical techniques designed to protect olfaction ${ }^{51}$ cannot be used for olfactory groove tumors: interfalcine approach, or removal of the ethmoid complex. ${ }^{52,53}$ Preservation of the contralateral olfactory filaments permits conservation of some olfactory sense for tumors that have developed unilaterally, as we observed in two cases.

The complications associated with the trans-sinusal frontal approach are twofold: infection and postoperative CSF fistulas. Infections are favored by the communication between the intracranial contents with the contaminated nasal cavity, by subperiosteal dissection depriving the bone of part of its vascularization, and finally by the duration of the intervention. Also, the importance of the deadspace and the difficulty of brain expansion in elderly can increase that risk. Infectious complications resulting from the penetration of the frontal sinus can be prevented by several surgical maneuvers: (1) cranialization of the frontal sinus with total exenteration of the mucous membranes, and obturation of the frontonasal ducts isolating the cranial cavity from the paranasal sinuses; and (2) watertight dural closure with a periosteum graft, reinforced by a free periosteum graft introduced on the dural defect in particular at the level of the sphenoid hyperostosis. The dural closure avoids CSF leaks. When the dura mater cannot be closed at the skull base, insertion of several periosteum fragments reinforced by fibrin glue between the dura and the bone avoids the development of a fistula trajectory and permits spontaneous sealing of leaks. Furthermore, suppression of the deadspace by periosteum is a factor acting against the development of infections. Closure and reconstruction could not be achieved with a transciliary subfrontal craniotomy, ${ }^{54}$ which does not justify taking large periosteum grafts. We also operate on ethmoid adenocarcinomas using the trans-sinusal approach. Reconstruction of the base is slightly different, as we use a vascularized periosteum graft, with bone chips and abdominal fat. 
The length of the scalp incision may be of concern. The bicoronal incision is long and may dispose to profuse bleeding. However, besides the excellent cosmetic result it allows, the bicoronal incision permits accurate fashioning of the bone flap without retracting soft tissues for exposure of the anterior wall of the sinus. To reduce operative time, blood loss, especially in case of hairline recession, deep forehead creases may be used to tailor the scalp incision. ${ }^{55}$

\section{CONCLUSIONS}

The trans-sinusal frontal approach was used for removal of six olfactory groove meningiomas, without any brain retraction or damage. The technique is easy to perform; it gives a direct subfrontal view of the base along its anterior floor, allows devascularization of the tumor at the initial stages, and creates a dry field, enabling dissection of the posterior poles of the tumor with a greater visibility. Reconstruction of the dura and possibly of the osseous skull base is permitted by the width of the working exposure. Cosmetic result is perfect with no resultant deformity. The indications of the trans-sinusal frontal approach can be spread to all tumors of the anterior floor of the skull base, without or with extension in the ethmoid and sphenoid sinuses and extending to the level of the diaphragm sellae and optic canals.

\section{COMMENTS FOR PUBLICATION}

The authors describe a cosmetically appealing variation of standard skull base approaches to anterior basal meningiomas. Their technical modification is well described and illustrated. The modification is based on sound craniofacial cosmetic principles as well as skull base surgery philosophical principles. It is a welcome addition to our increasingly diverse armamentarium for these chal- lenging lesions. For the sake of thoroughness, I would call the authors' and our readers' attention to two additional new minimally invasive approaches to lesions in this region that were not discussed in this manuscript. ${ }^{1,2}$

Mark E. Linskey, M.D. Associate Professor of Neurological Surgery University of Arkansas for Medical Sciences Little Rock, AR, USA

1. Jho HD. Orbital roof craniotomy via an eyebrow incision: a simplified anterior skull base approach. Minimally Invasive Neurosurg 1997;40:91-97

2. Jho HD, Ko Y. Glabellar approach: simplified midline anterior skull base approach. Minimally Invasive Neurosurgery 1997;40:62-67

\section{REFERENCES}

1. Cushing H, Eisenhardt L. The olfactory groove meningiomas with primary anosmia. In: Meningiomas: Their Classification, Regional Behavior, Life History and Surgical End Results. Springfield, IL: Charles C Thomas, 1938:250-273

2. Mayfrank L, Gilsbach JM. Interhemispheric approach for microsurgical removal of olfactory groove meningiomas. $\mathrm{Br}$ J Neurosurg 1996;10:541-545

3. Babu R, Barton A, Kasoff SS. Resection of olfactory groove meningiomas: technical note revisited. Surg Neurol 1995; 44:567-572

4. Delfini R, Iannetti G, Belli E, et al. Cranio-facial approaches for tumors involving the anterior half of the skull base. Acta Neurochir (Wien) 1993;124:53-60

5. Fujitsu K, Saijoh M, Aoki F, et al. Telecanthal approach for meningiomas in the ethmoid and sphenoid sinuses. Neurosurgery 1991;28:714-720

6. Kawakami K, Yamanouchi Y, Kubota C, et al. An extensive transbasal approach to frontal skull-base tumors. Technical note. J Neurosurg 1991;74:1011-1013

7. Kawakami K, Yamanouchi Y, Kawamura Y, Matsumura H. Operative approach to the frontal skull base: extensive transbasal approach. Neurosurgery 1991;28:720-725

8. Sekhar LN, Nanda A, Sen CN, et al. The extended frontal approach to tumors of the anterior, middle, and posterior skull base. J Neurosurg 1992;76:198-206

9. Sen C, Sekhar LN. An extended subfrontal approach to the skull base. In: Rengachary SS, Wilkins RH, eds. Neurosurgical Operative Atlas. Vol 2. Baltimore: Williams \& Wilkins, 1992:97-106 
10. Derome P. Les tumeurs sphéno-ethmoidales. Possibilités d'exérèse et de réparation chirurgicales. Neurochirurgie 1972;18(suppl 1):1-164

11. Kempe LG. Olfactory groove meningioma. In: Operative Neurosurgery. Vol 1. New York: Springer-Verlag; 1968:104-108

12. Hassler W, Zentner J. Pterional approach for surgical treatment of olfactory groove meningiomas. Neurosurgery 1989;25:942-947

13. Paterniti S, Fiore $\mathrm{P}$, Levita A, et al. Venous saving in olfactory meningioma's surgery. Clin Neurol Neurosurg 1999; 101:235-237

14. Turazzi S, Cristofori L, Gambin R, Bricolo A. The pterional approach for the microsurgical removal of olfactory groove meningiomas. Neurosurgery 1999;45:821-826

15. Yasargil MG. Microneurosurgery of CNS Tumors. Vol IVB. New York: Thieme, 1996:140-141

16. Al Mefty O. Surgical technique for the juxta-sellar area. In: Surgery of the Cranial Base. Boston: Kluwer Academic Publishers; 1989:73-89

17. Béziat JL, Pierluca P. Les lésions traumatiques des confins crânio-faciaux. Démarche diagnostique et indications thérapeutiques. Lyon Chir 1984;80:333-336

18. Béziat JL, Pierluca P, Freidel M. L'abord des lésions traumatiques des confins crânio-faciaux par voies trans- lésionnelle et trans-sinusienne. Ann Chir Plast Esthet 1985;30: 236-240

19. Béziat JL, Rémond J, Pialat J, Mazoyer JF. Les voies d'abord faciales des structures médianes de la base du crâne. Rev Stomatol Chir Maxillofac 1997;98:183-206

20. Villette L, Lepoutre F, Lesoin F, et al. Traitement des brèches ostéo-durales de l'étage antérieur de la base du crâne par voie trans-lésionnelle. A propos de 25 cas opérés en double équipe neurochirurgicale et maxillo-faciale. Rev Stomatol Chir Maxillofac 1989;90:73-78

21. Hallacq P, Moreau JJM, Fischer G, Béziat JL. Voie trans-sinusienne frontale pour les méningiomes de la gouttière olfactive. Note technique. Neurochirurgie 1999;45:329337

22. Bonnal J, Sedan R, Paillas JE. Problèmes cliniques, évolutifs et thérapeutiques soulevés par les méningiomes envahissants de la base du crâne. Neurochirurgie 1961;2:108-117

23. Hallacq P. Abords antérieurs de la base du crâne. Anatomie, techniques et complications, indications. Vol I. University of Lyon: Mémoire DES Neurochirurgie; 1995

24. Gibson T, Walker FM. Large osteoma of the frontal sinus. A method of removal to minimise scarring and prevent deformity. Br J Plast Surg 1951;4:210-217

25. MacBeth R. The osteoplastic operation for chronic infection of the frontal sinus. Laryngol Otol 1954;68:465-477

26. Tato JM, Sibbald DW, Bergaglio OE. Surgical treatment of the frontal sinus by the external route. Laryngoscope 1954;64:504-521

27. Bergara AR, Itoiz AO. Present state of the surgical treatment of chronic sinusitis. AMA Arch Otolaryngol 1955; 61:616-628
28. Goodale RL, Montgomery WW. Anterior osteoplastic frontal sinus operation. Five years' experience. Ann Otol Rhinol Laryngol 1961;70:860-880

29. Montgomery WW. Osteoplastic frontal sinus operation: coronal incision. Ann Otol Rhinol Laryngol 1965;74: 821-830

30. Malecki J. New trends in frontal sinus surgery. Acta Otolaryngol (Stockh) 1959;50:137-140

31. Colohan ART, Jane JA, Newman SA, Maggio WW. Frontal sinus approach to the orbit. Technical note. J Neurosurg 1985;63:811-813

32. Colohan ART, Jane JA, Park TS, Persing JA. Bifrontal osteoplastic craniotomy utilizing the anterior wall of the frontal sinus: technical note. Neurosurgery 1985;16:822-824

33. Jane JA. Frontal approach to orbital and parasellar structures. In: Wilson CB, eds. Neurosurgical Procedures. Personal Approaches to Classic Operations. Baltimore: Williams \& Wilkins, 1992:10-20

34. Persing JA, Jane JA, Levine PA, Cantrell RW. The versatile frontal sinus approach to the floor of the anterior cranial fossa. J Neurosurg 1990;72:513-516

35. Ojemann RG. Meningiomas of the basal parapituitary region: technical considerations. Clin Neurosurg 1980;233262

36. Ojemann RG. Olfactory groove meningiomas. In: AlMefty O, ed. Meningiomas. New York: Raven Press, 1991:383-393

37. Seeger W. Frontobasal operations. In: Microsurgery of the Cranial Base. Berlin: Springer-Verlag; 1983:200-269

38. Snyderman CH, Costantino PD, Sekhar LN. Anterior approaches to the cranial base. In: Apuzzo MLJ, ed. Brain Surgery: Complication Avoidance and Management. New York: Churchill Livingstone, 1993:2265-2281

39. Biedlingmaier JF, Lester $\mathrm{N}$. The free bone flap approach to the frontal sinus in the high-risk orbital patient. Laryngoscope 1995;105:1138-1140

40. Cophignon J, George B, Marchac D, Roux F. Voie transbasale élargie par mobilisation du bandeau fronto-orbitaire médian. Neurochirurgie 1983;29:407-410

41. Lesoin F, Pellerin P, Villette L, et al. Mobilisation du bandeau fronto-orbitaire médian par volet monobloc. Neurochirurgie 1986;32:161-163

42. Roux FX, Devaux B, Nataf F, et al. Tumeurs malignes de la région ethmoidale. Techniques neurochirurgicales. Neurochirurgie 1997;43:92-99

43. Darrouzet V, San-Galli F, Portmann D, et al. La voie trans-fronto-nasale. Evolution de la chirurgie par voie mixte des tumeurs ethmoidales. Expérience de 12 cas. Rev Laryngol 1993;114:217-220

44. Pinsolle J, San-Galli F, Siberchicot F, et al. Modified approach for ethmoid and anterior skull base surgery. Arch Otolaryngol 1991;117:779-782

45. Raveh J, Laedrach K, Speiser M, et al. The subcranial approach for fronto-orbital and anteroposterior skull-base tumors. Arch Otolaryngol Head Neck Surg 1993;119:385-393

46. Auque J, Civit Th. Les dangers du sacrifice du sinus longitudinal supérieur dans son tiers antérieur lors de la 
chirurgie des méningiomes olfactifs. Neurochirurgie 1996; 42(suppl 1):84-87

47. Bret P, Trepsat F, Massini B, et al. Exclusion d'une malformation artério-veineuse de la gouttière olfactive gauche par ligature endo-orbitaire des artères ethmoidales. Neurochirurgie 1986;32:440-447

48. Salibi BS, Myers WO, Gildersleeve JW. En bloc removal of large bilateral olfactory groove meningioma. Surg Neurol 1978;9:264-266

49. Simpson D. The recurrence of intracranial meningiomas. J Neurol Neurosurg Psychiatry 1957;20:22-39

50. Samii M, Draf W. Surgery of the Skull Base. An Interdisciplinary Approach. Berlin: Springer-Verlag; 1989

51. Fujitsu K, Sekino T, Sakata K, Kawasaki T. Basal interfalcine approach through a frontal sinusotomy with vein and nerve preservation. J Neurosurg 1994;80:575-579
52. Sepehrnia A, Knopp U. Preservation of the olfactory tract in bifrontal craniotomy for various lesions of the anterior cranial fossa. Neurosurgery 1999;44:113-117

53. Spetzler RF, Herman JM, Beals S, et al. Preservation of olfaction in anterior craniofacial approaches. J Neurosurg 1993;79:48-52

54. Sanchez-Vasquez MA, Barrera-Calatayud P, Meija-Villela $\mathrm{M}$, et al. Transciliary subfrontal craniotomy for anterior skull base lesions. Technical note. J Neurosurg 1999;91: 892-896

55. Cheney ML, Gliklich R, Li KK, et al. Midforehead incision. An approach to the frontal sinus and upper face. J Craniofac Surg 1995;6:408-411 